\title{
On the Difficulty to Design Arabic E-learning System in Statistics
}

\author{
Taleb Ahmad* \\ Wolfgang Härdle* \\ Julius Mungo*
}

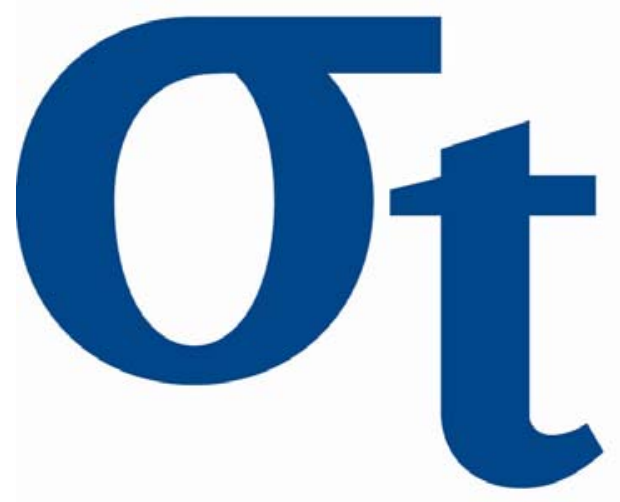

9)

寸

6

* Department of Statistics, Humboldt-Universität zu Berlin, Germany 


\title{
On the Difficulty to Design Arabic E-learning System in Statistics *
}

\author{
Taleb Ahmad - Wolfgang Härdle - Julius Mungo \\ Humboldt-Universität zu Berlin \\ Department of Statistics \\ Spandauer Str. 1 \\ D-10178 Berlin
}

March 22, 2006

\begin{abstract}
In this paper, we present a case study, which describe the development of the Statistic e-learning-course in Arabic language -"Arabic MM*STAT". The basic frame for this E-book, the system MM*STAT was developed at the School for Business and Economics of Humboldt-Universität zu Berlin. Arabic MM*STAT uses a HTML - based filing card structure. We discuss the difficulties of the implementation of such a system in to the standard WWW formats and present the solutions needed for Arab educational institutions and the Arabic user. Those solutions are consistent with the Arabic language, and include the modern trend in the e-learning environment.
\end{abstract}

Keywords: electronic books, Arabtex, MM*STAT, Statistical software.

JEL Classification I21, C19

*This research was supported by the Deutsche Forschungsgemeinschaft through the SFB 649 'Economic Risk'. Corresponding author: Taleb Ahmad, Center for Applied Statistics and Economics, HumboldtUniversität zu Berlin, Department of Statistics, Spandauer Str. 1, D-10178 Berlin, Germany, email: tahmad@wiwi.hu-berlin.de 


\section{Introduction}

E-Learning is the modern model of education, transferring the classical text books to an electronic medium. It has become an important stream of education in present and has a promising future. E-Learning uses net work technology to manage, design, deliver, select, and extend classical learning. Our approach, based on the MM*STAT, provides a flexible e-learning Statistic environment, created at the institute of Statistics and Economics of the Humboldt Universität zu Berlin. It provides e-learning of Statistics in many languages that include English, German, French, Polish, Czech, Spanish, Italian ; see http://www.mdstat.com. Our main aim in this project is to extend e-learning concept to include the Arabic language. Originally the MD*Book is a flexible user interface tool for generating user interactive e-learning documents such as MM*STAT. This tool uses the LaTeX format file to enable compilation into PDF, Java, HTML. We aim to use the LaTeX file format for creating an Arabic text. As we will show this remains a problem, basically caused by the incompatibility of the standard Latex $2 \mathrm{html}$ with the phenomenons of the Arabic typography. The learning system (Arabic MM*STAT) has been implemented in the website: http://www.mdstat.com. In what follows, we present in section 2 an Arabic MM*STAT description. And discuss in section 3 the difficulties to design the Arabic MM*STAT which involves the Arabic style and the technical problems. In section 4 we summarize our work, given a direction for the future on Arabic LaTeX. 


\section{Arabic MM*STAT}

Arabic MM*STAT is a Web-based learning platform that provides a fully integrated student environment to learn statistics. MM*STAT allows an interactive introduction into the world of statistics. The goal of Arabic MM*STAT designer is :

1. To contribute to the evolution of Statistics e-learning by the development of an efficient system.

2. To create an Arabic MM*STAT, because there were not enough Arabic statistic elearning platforms. The purpose of this study is to develop a platform that will be used completely in Arabic, together with other languages such as English and German.

We know that the Arabic language is different from English and other languages in a number of respects:

1. Arabic language is written from right to left.

2. It is possible to form hundreds of words from one root word (al- Fedaghi and alSadoun, 1990).

3. In Arabic the definite article and prepositions, are not separated from their following word by a space, on another hand some words have different meanings but have the same written form.

4. The peculiar morphology of Arabic might render methods used for English text retrieval inappropriate. For example, the English phrase "and she wrote it" comprising of four words would be written in Arabic as one word "wakatabathu" (wa=and, kataba=wrote, $\mathrm{t}=$ she,hu=it). Moukdad, H., Andrew, L., (2001). Generally, the difficulty with someone who has translated a software product into another language to get a realistic picture of the challenges. Not only are there vocabularies the translator might not know, but they also must adapt sentence structure, significance, and colloquialisms to convey equivalent meaning. 


\section{Difficulties to design, an Arabic MM*STAT}

We now discuss some practical and technical problems. The development of MM*Stat by (Müller, M., Rönz, B., Ziegenhagen, U., 2000) has been the first step in the transition from traditional textbooks to integrated learning environments. This project is with multiple languages and our goal is to apply this project in Arabic language. To do this, one needs Arabic Windows XP version, as a tool to write the Arabic code. We then have to translate our articles in Arabic Microsoft Word, and save the files with unicode (file.unicode). Another problem is the direction. Writing in Arabic is from right to left but the direction in HTML appears from left to right, which technical problem for working in Arabic. What is the solution for this problem? To solve this problem we use the code dir = "rtl" in HTML file at every paragraph and link - Figure - Table and the statistics forms, then the direction of the writing changes from right to left.

MD*Book Software environment requires LaTeX. Another problem is the LaTeX Format. Arab text does not work with LaTeX. We aim to finding a solution to this problem in our project. There was a project for Arabtex in LaTeX presented by Prof. Klaus Lagally Universitt Stuttgart. This project was a good step but it is not enough, because the letter in Arab text in this project was written with English, not with Arabic and this project did not have the ability to reduce Statistics on an Arabic Website. This project uses only PDF, not HTML. To summarize, the goal of my work is to create an electronic book in Arabic using LaTeX source code and the MD*Book tool. 


\section{Arabic MM*STAT Realisation}

Figure 1 presents Arabic MM*STAT - Cover Page. Figure 2 presents Arabic MM*STAT

- Content Page. The user can enter the courses topics via a list of contents and can go to any desired topic or course chapter. By hovering the mouse pointer over a selected course file for a few seconds will appear to identify the course topic.

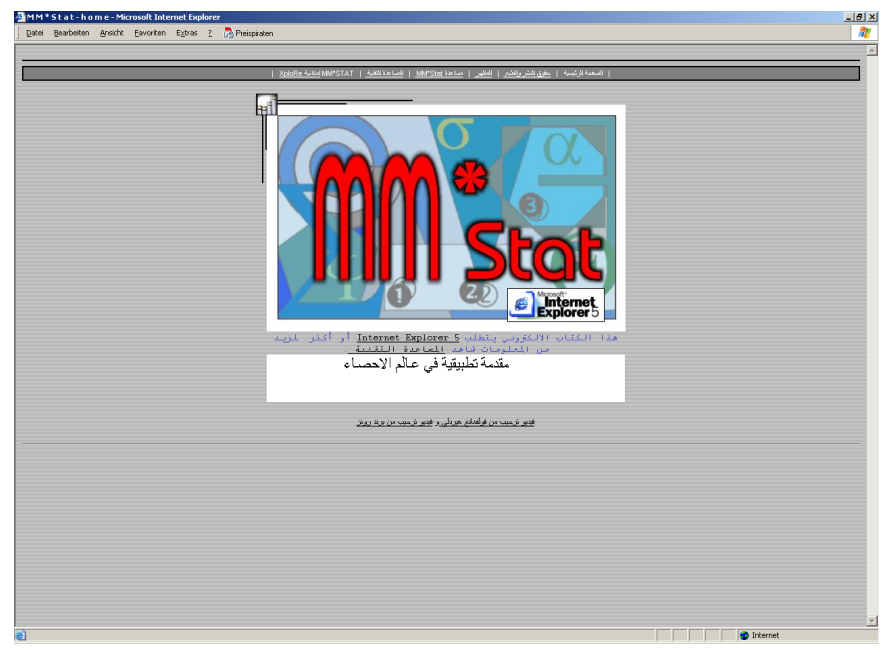

Figure 1: Arabic MM*STAT - Cover Page

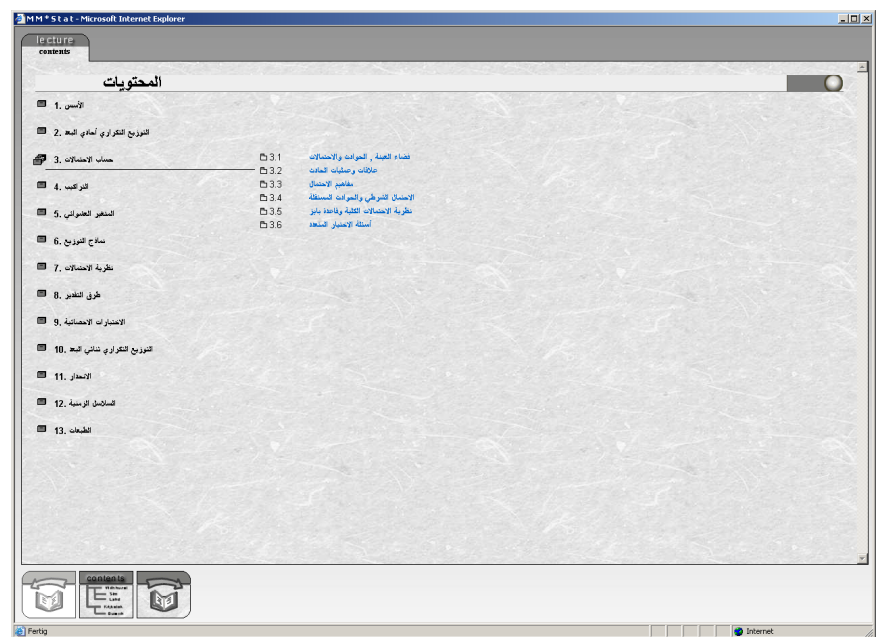

Figure 2: Arabic MM*STAT - Content Page

Figure 3 shows a graphical user interface (GUI) of a statistic topic in Arabic MM*STAT 
and Figure 4 shows the corresponding English version.

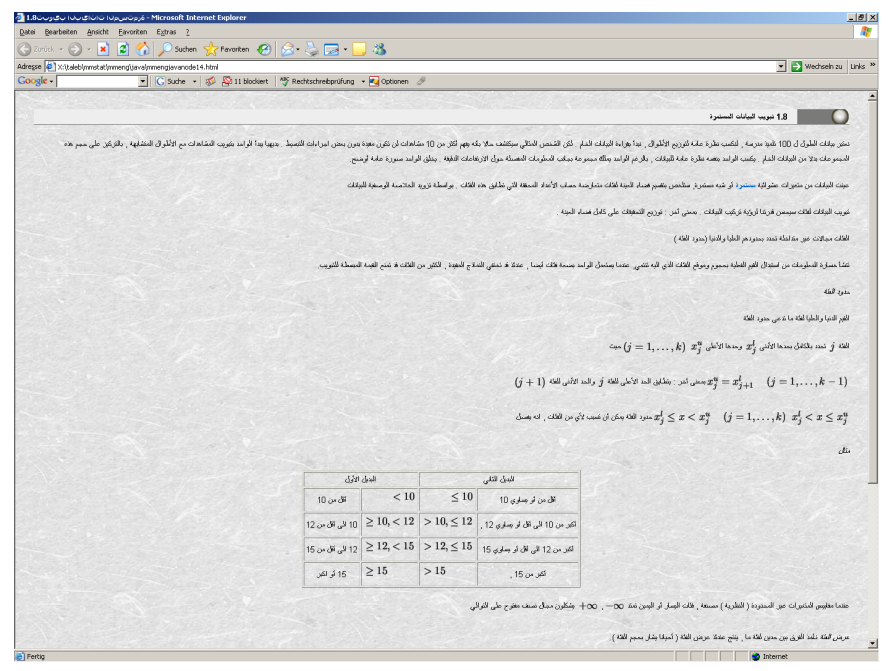

Figure 3: Arabic MM*Stat: Layer Architecture and Screenshot

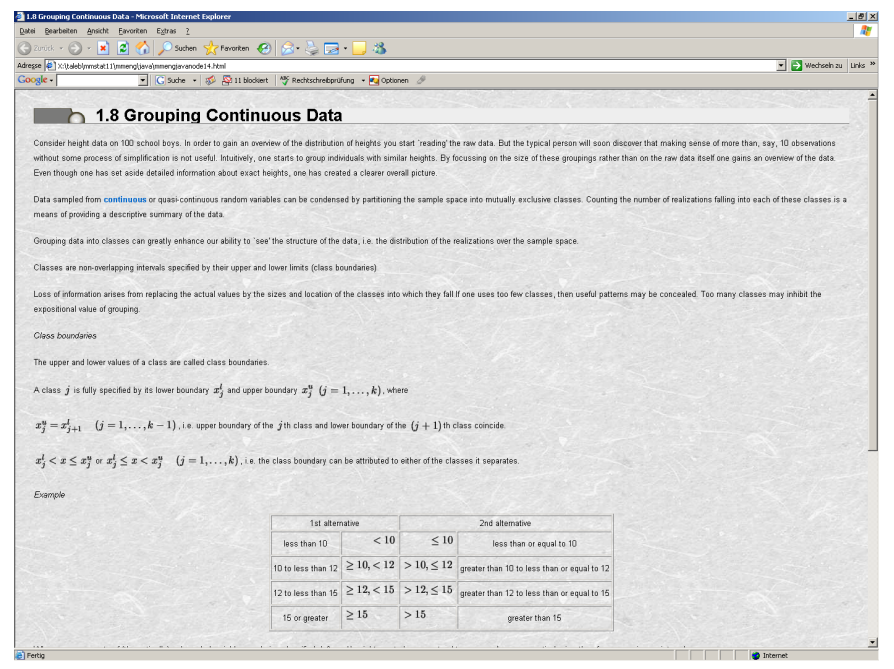

Figure 4: English MM*Stat: Layer Architecture and Screenshot

The Arabic MM*STAT Course has five components structures; the lecture, information, explained, enhanced and interactive. Each lecture gives the basic concepts of the general statistical theory, definitions, formulae, mathematical proofs. Arabic MM*Stat provides the students to compute distribution functions, graphics and derive results for statistical tests. The students or anyone interested in statistics can interactively learn about basic concepts of statistics at any time and anywhere. 


\section{Conclusion}

This is the possibility of creating an e-learning system with Arabic MM*STAT. And discussed the problems encountered, both in the context of the Arabic language itself and the technical problems, which is the nonexistence of a possibility to use LaTeX code in Arabic. Our next goal is to explore possible solutions to the problem of Arabic LaTeX. Actually the goal has to do with XML.

\section{References}

AbdulJaleel, N., Larkey, L., English to Arabic Transliteration for Information Retrieval: A Statistical Approach, Center for Intelligent Information Retrieval Computer Science, University of Massachusetts.

Al-Fedaghi, S and H. Al-Sadoun. Morphological compression of Arabic text. Information Processing Management 26(2): 30316., 1990.

Bates, T., Forum on National strategies for E-learning, IIEP Virtual Institute, 21 October to 15 November 2002 .

Jemni, M., Bahattab, A., A collaborative approach for development of arabic courses for E-learning, a case study of Tunisian-Saudi Arabian experience.

Hammad, S., AL-ayyoub,A.,Sarie,T., combining existing E-learning components towards an ivle, Arab Open University, Amman.

Härdle,W., Klinke,S., Ziegenhagen,U., eLearning - A Critical Review, Humboldt-Universität zu Berlin, January 5, 2006. 
Lagally, K., ArabTeX : a System for Typesetting Arabic : User Manual Version 3.00, Universitt Stuttgart, 1993.

Mungo, J., e-learning/e-teaching An Implementation and Evaluation of a Finance Introductory Course, Humboldt-Universität zu Berlin, 2004.

Moukdad, H., Andrew, L., Information Retrieval from Full-Text Arabic Databases,Can Search Engines Designed for English Do the Job?,Canada, 2001.

Müller, M., Rönz, B., Ziegenhagen, U., The Multimedia Project MM*Stat for Teaching Statistics, In COMPSTAT. Proceedings in Computational Statistics, Physica Verlag,(2000).

Maegaard, B., Choukri, K., Mokbel, C., Yaseen, M., Language Technology for Arabic, NEMLAR, Center for Sprogteknolo gi. University of Copenhagen, July 2005.

Zahran, S., Promotion of Development-Oriented ICT Applications for E-Learning, Western Asia Preparatory Conference for the World Summit on the Information Society (WSIS), Beirut, 4-6 February 2003. 


\section{SFB 649 Discussion Paper Series 2006}

For a complete list of Discussion Papers published by the SFB 649, please visit http://sfb649.wiwi.hu-berlin.de.

001 "Calibration Risk for Exotic Options" by Kai Detlefsen and Wolfgang K. Härdle, January 2006.

002 "Calibration Design of Implied Volatility Surfaces" by Kai Detlefsen and Wolfgang K. Härdle, January 2006.

003 "On the Appropriateness of Inappropriate VaR Models" by Wolfgang Härdle, Zdeněk Hlávka and Gerhard Stahl, January 2006.

004 "Regional Labor Markets, Network Externalities and Migration: The Case of German Reunification" by Harald Uhlig, January/February 2006.

005 "British Interest Rate Convergence between the US and Europe: A Recursive Cointegration Analysis" by Enzo Weber, January 2006.

006 "A Combined Approach for Segment-Specific Analysis of Market Basket Data" by Yasemin Boztuğ and Thomas Reutterer, January 2006.

007 "Robust utility maximization in a stochastic factor model" by Daniel Hernández-Hernández and Alexander Schied, January 2006.

008 "Economic Growth of Agglomerations and Geographic Concentration of Industries - Evidence for Germany" by Kurt Geppert, Martin Gornig and Axel Werwatz, January 2006.

009 "Institutions, Bargaining Power and Labor Shares" by Benjamin Bental and Dominique Demougin, January 2006.

010 "Common Functional Principal Components" by Michal Benko, Wolfgang Härdle and Alois Kneip, Jauary 2006.

011 "VAR Modeling for Dynamic Semiparametric Factors of Volatility Strings" by Ralf Brüggemann, Wolfgang Härdle, Julius Mungo and Carsten Trenkler, February 2006.

012 "Bootstrapping Systems Cointegration Tests with a Prior Adjustment for Deterministic Terms" by Carsten Trenkler, February 2006.

013 "Penalties and Optimality in Financial Contracts: Taking Stock" by Michel A. Robe, Eva-Maria Steiger and Pierre-Armand Michel, February 2006.

014 "Core Labour Standards and FDI: Friends or Foes? The Case of Child Labour" by Sebastian Braun, February 2006.

015 "Graphical Data Representation in Bankruptcy Analysis" by Wolfgang Härdle, Rouslan Moro and Dorothea Schäfer, February 2006.

016 "Fiscal Policy Effects in the European Union" by Andreas Thams, February 2006.

017 "Estimation with the Nested Logit Model: Specifications and Software Particularities" by Nadja Silberhorn, Yasemin Boztuğ and Lutz Hildebrandt, March 2006.

018 "The Bologna Process: How student mobility affects multi-cultural skills and educational quality" by Lydia Mechtenberg and Roland Strausz, March 2006.

019 "Cheap Talk in the Classroom" by Lydia Mechtenberg, March 2006.

020 "Time Dependent Relative Risk Aversion" by Enzo Giacomini, Michael Handel and Wolfgang Härdle, March 2006.

021 "Finite Sample Properties of Impulse Response Intervals in SVECMs with Long-Run Identifying Restrictions" by Ralf Brüggemann, March 2006.

022 "Barrier Option Hedging under Constraints: A Viscosity Approach" by Imen Bentahar and Bruno Bouchard, March 2006.

\section{SFB 649, Spandauer Straße 1, D-10178 Berlin} http:/ / sfb649.wiwi.hu-berlin.de

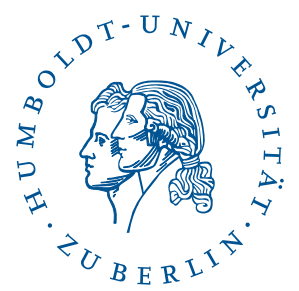


023 "How Far Are We From The Slippery Slope? The Laffer Curve Revisited" by Mathias Trabandt and Harald Uhlig, April 2006.

024 "e-Learning Statistics - A Selective Review" by Wolfgang Härdle, Sigbert Klinke and Uwe Ziegenhagen, April 2006.

025 "Macroeconomic Regime Switches and Speculative Attacks" by Bartosz Maćkowiak, April 2006.

026 "External Shocks, U.S. Monetary Policy and Macroeconomic Fluctuations in Emerging Markets" by Bartosz Maćkowiak, April 2006.

027 "Institutional Competition, Political Process and Holdup" by Bruno Deffains and Dominique Demougin, April 2006.

028 "Technological Choice under Organizational Diseconomies of Scale" by Dominique Demougin and Anja Schöttner, April 2006.

029 "Tail Conditional Expectation for vector-valued Risks" by Imen Bentahar, April 2006.

030 "Approximate Solutions to Dynamic Models - Linear Methods" by Harald Uhlig, April 2006.

031 "Exploratory Graphics of a Financial Dataset" by Antony Unwin, Martin Theus and Wolfgang Härdle, April 2006.

032 "When did the 2001 recession really start?" by Jörg Polzehl, Vladimir Spokoiny and Cătălin Stărică, April 2006.

033 "Varying coefficient GARCH versus local constant volatility modeling. Comparison of the predictive power" by Jörg Polzehl and Vladimir Spokoiny, April 2006.

034 "Spectral calibration of exponential Lévy Models [1]" by Denis Belomestny and Markus Reiß, April 2006.

035 "Spectral calibration of exponential Lévy Models [2]" by Denis Belomestny and Markus Reiß, April 2006.

036 "Spatial aggregation of local likelihood estimates with applications to classification" by Denis Belomestny and Vladimir Spokoiny, April 2006.

037 "A jump-diffusion Libor model and its robust calibration" by Denis Belomestny and John Schoenmakers, April 2006.

038 "Adaptive Simulation Algorithms for Pricing American and Bermudan Options by Local Analysis of Financial Market" by Denis Belomestny and Grigori N. Milstein, April 2006.

039 "Macroeconomic Integration in Asia Pacific: Common Stochastic Trends and Business Cycle Coherence" by Enzo Weber, May 2006.

040 "In Search of Non-Gaussian Components of a High-Dimensional Distribution" by Gilles Blanchard, Motoaki Kawanabe, Masashi Sugiyama, Vladimir Spokoiny and Klaus-Robert Müller, May 2006.

041 "Forward and reverse representations for Markov chains" by Grigori N. Milstein, John G. M. Schoenmakers and Vladimir Spokoiny, May 2006.

042 "Discussion of 'The Source of Historical Economic Fluctuations: An Analysis using Long-Run Restrictions' by Neville Francis and Valerie A. Ramey" by Harald Uhlig, May 2006.

043 "An Iteration Procedure for Solving Integral Equations Related to Optimal Stopping Problems" by Denis Belomestny and Pavel V. Gapeev, May 2006.

044 "East Germany's Wage Gap: A non-parametric decomposition based on establishment characteristics" by Bernd Görzig, Martin Gornig and Axel Werwatz, May 2006.

045 "Firm Specific Wage Spread in Germany - Decomposition of regional differences in inter firm wage dispersion" by Bernd Görzig, Martin Gornig and Axel Werwatz, May 2006.

\section{SFB 649, Spandauer Straße 1, D-10178 Berlin http:/ / sfb649.wiwi.hu-berlin.de}

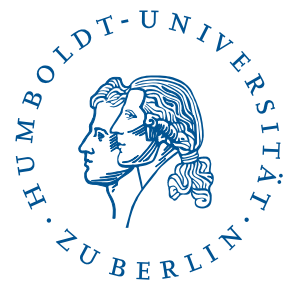


046 "Produktdiversifizierung: Haben die ostdeutschen Unternehmen den Anschluss an den Westen geschafft? - Eine vergleichende Analyse mit Mikrodaten der amtlichen Statistik" by Bernd Görzig, Martin Gornig and Axel Werwatz, May 2006.

047 "The Division of Ownership in New Ventures" by Dominique Demougin and Oliver Fabel, June 2006.

048 "The Anglo-German Industrial Productivity Paradox, 1895-1938: A Restatement and a Possible Resolution" by Albrecht Ritschl, May 2006.

049 "The Influence of Information Costs on the Integration of Financial Markets: Northern Europe, 1350-1560" by Oliver Volckart, May 2006.

050 "Robust Econometrics" by Pavel Čížek and Wolfgang Härdle, June 2006.

051 "Regression methods in pricing American and Bermudan options using consumption processes" by Denis Belomestny, Grigori N. Milstein and Vladimir Spokoiny, July 2006.

052 "Forecasting the Term Structure of Variance Swaps" by Kai Detlefsen and Wolfgang Härdle, July 2006.

053 "Governance: Who Controls Matters" by Bruno Deffains and Dominique Demougin, July 2006.

054 "On the Coexistence of Banks and Markets" by Hans Gersbach and Harald Uhlig, August 2006.

055 "Reassessing Intergenerational Mobility in Germany and the United States: The Impact of Differences in Lifecycle Earnings Patterns" by Thorsten Vogel, September 2006.

056 "The Euro and the Transatlantic Capital Market Leadership: A Recursive Cointegration Analysis" by Enzo Weber, September 2006.

057 "Discounted Optimal Stopping for Maxima in Diffusion Models with Finite Horizon" by Pavel V. Gapeev, September 2006.

058 "Perpetual Barrier Options in Jump-Diffusion Models" by Pavel V. Gapeev, September 2006.

059 "Discounted Optimal Stopping for Maxima of some Jump-Diffusion Processes" by Pavel V. Gapeev, September 2006.

060 "On Maximal Inequalities for some Jump Processes" by Pavel V. Gapeev, September 2006.

061 "A Control Approach to Robust Utility Maximization with Logarithmic Utility and Time-Consistent Penalties" by Daniel Hernández-Hernández and Alexander Schied, September 2006.

062 "On the Difficulty to Design Arabic E-learning System in Statistics" by Taleb Ahmad, Wolfgang Härdle and Julius Mungo, September 2006.

SFB 649, Spandauer Straße 1, D-10178 Berlin http:/ / sfb649.wiwi.hu-berlin.de 